\title{
A New Equity Deal for Schools: \\ A case study of policymaking in Queensland, Australia
}

Parlo Singh and Sandra Taylor

\section{Contact Details:}

Parlo Singh, Griffith University: parlo.singh@griffith.edu.au

Sandra Taylor, QUT, s.taylor@qut.edu.au

Publication Details:

Singh, P. \& Taylor, S. (2007). A New Equity Deal for Schools: A Case Study of Policy Making in Queensland, Australia. British Journal of Sociology of Education, 28(3), 301-315.

Copyright: Taylor\&Francis

\begin{abstract}
:
In this paper we draw on concepts from policy sociology (Apple, 2002, Ball, 2003; 1990, Bernstein, 2000, Foucault, 1979, 1990) to analyse the new equity deal for schools in Queensland, Australia. We examine this 'new deal' through an analysis of the language of 'inclusion' and 'educational risk' in key policy documents associated with a major reform of public education in Queensland. In addition, we analyse the interview talk of key policy actors involved in policy framing, carriage and monitoring. We contextualize our concerns about equity issues in terms of the global information revolution. As Castells (2000) has noted globalism has increased rather than reduced social inequality. Good quality accessible education plays a role in challenging the inequalities produced by global informationalism. In Education Queensland, equity is still on the agenda, but in radically new neo-liberal economic ways. The focus is individualistic - each individual needs to be tracked because they are potentially 'at-risk' of 'school failure'. Identification of 'at-risk' students has been devolved to the level of the school and district and intervention strategies have to be devised at the local level. Stories of success are then to be shared/networked with other schools. We suggest that while 'target group equity' strategies were limited in terms of addressing issues of social exclusion and inequity in the new millennium, the new deal on equity, a market-individualistic approach is an inadequate alternative.
\end{abstract}




\title{
A New Equity Deal for Schools: A case study of policymaking in Queensland, Australia
}

\begin{abstract}
Parlo Singh and Sandra Taylor
In tough times you stick together. ... This was Labor's 'inclusive' society: a social democracy sustained by the wealth-generating power of free markets and economic integration with the world economy, and made strong by a practical ethic of social cooperation and fair distribution. (Watson, 2002, p.316).
\end{abstract}

\section{Introduction}

In this paper, we are interested in how the terms inclusion and educational risk were appropriated in the debates about what constitutes equitable education in Queensland, Australia. In particular, we are interested in the 'policy regimes' or 'interrelated ensemble of policies' (Ball, 2003, p.30) produced by Education Queensland during a period of Labor government rule and under conditions of global informationalism. In the case of Education Queensland, these policy regimes comprise the set of background, research and discussion papers produced prior to the formulation of the vision statement Queensland State Education 2010 (hereafter: QSE 2010), as well as the departmental papers and interview talk of key policy actors responsible for policy formulation and implementation in the early years of the new millennium (see for example: Cullen, Cosier, Greco, \& Payne, 1999; Edgar, 1999; Education Queensland, 2000, 2001a, 2001b, 2002; Luke, 1999; Martinez, 1999; Schofield, 1999a, 1999b). These various documents were produced as part of a major reform of schooling in Queensland, Australia and in response to global change (Taylor and Henry, 2003).

A number of researchers have suggested that global informationalism has exacerbated social inequality. For example, Castells (2000) argues that social inequality has increased through: (a) the differential distribution of resources (collective wealth) and (b) practices of social exclusion through an increase in exploitable work practices. In terms of the distribution of wealth/resources, there is growing income disparity and increasingly large cohorts of people are experiencing poverty (see also Cole, 2003; Smyth, 2004). In addition, the social relation to the means of production has become increasingly individualized, casualized, and routinized through a growth in 'McJobs' (see Dwyer \& Wyn, 2001; Luke, 1999). This has meant that vulnerable members of society (women, minorities, children, refugees) are increasingly susceptible to further exploitation. Those with higher levels of specialist education are better positioned to compete for jobs that pay well, provide continuous employment and offer leave entitlements. At the same time, increased participation in post-compulsory education - fuelled simultaneously by the collapse of the youth employment market and the rhetoric of government policy - does not necessarily translate into highly paid skilled work. There is no direct one-to-one relation between the markets of education and the workplace (Dwyer \& Wynn, 2001). In addition, some theorists have argued that the dominant economic rationalist views of education policies have eroded some of the gains made in terms of recognitive justice (see Taylor \& Singh, 1995). By the term recognitive justice, we refer to the cultural aspects of inequality and the recognition of difference in terms of gender, ethnicity, disability and sexuality.

In terms of educational policy, we suggest that the mantra of 'inclusion' became 'policy speak', that is, the dominant way of talking and thinking about educational reform and equity in Queensland, Australia (see Gale \& Densmore, 2003). For some policy actors who were involved with the reform of the Queensland schooling sector, words like inclusion and educational risk were used to think and talk about what they were doing and why. For others, the terms were used as drivers for pushing forward a reform agenda. In 
this paper, we analyse the struggles over redefining equity agendas in schooling within this new 'inclusive mantra'. In the following section, we define what we mean by the terms policy and policy regimes in the context of global informationalism. We then move on to discuss the particular case study of educational reform in Queensland reported in this paper, and provide details of the data collection and analysis methods we used. In the third section, we analyse the competing, complementary, and contradictory meanings associated with the terms inclusion and educational risk. These terms, we suggest, came to constitute part of the new discursive regime about equity and schooling in Queensland, Australia. In the final section we discuss the implications of the study for educational policy particularly as it pertains to equity issues in a globalised context.

\section{Policy as Discourse and Text}

Recent approaches in policy sociology have been influenced by discourse theory perspectives, and policy processes have come to be viewed as text and discourse (Ball, 1990; Bowe et al., 1992; Taylor, 1997). Policy as discourse refers to the power and control principles or ensemble of rules generating policy texts (see Bernstein, 2000). In other words, policy as discourse refers to the rules governing what can be spoken/written, when, where, how, and by whom (see Foucault, 1990). Moreover, policy discourses are not only 'ways of talking about and conceptualizing policy', but they are also 'practices that systematically form the objects of which they speak' (Foucault cited in Ball, 1990, p.17). Thus policy discourses serve a double role, producing texts and thus constituting educational systems, pedagogic identities and practices and also interpreting possibilities for strategic action from existing practices and texts (see Foucault, 1979, 1990).

Policy as text refers to the documents which capture the meanings of the struggles, conflicts, and representative interests of various actors involved in their production (Gale \& Dinsmore, 2003). Thus, contradictory and conflicting meanings about equity may be captured in policy texts via the jostling between various policy actors positioned in different sections or arenas of the bureaucracy. An arena is a social space of conflict in which various agents compete over valued resources (Bernstein, 2000). These resources can take various forms, for example, they maybe economic (funds for schooling) or symbolic (language representing the needs of various groups). Moreover, agents, resources and arenas never stay static or fixed. For example, policy actors' struggles over definitions of equity are essentially struggles over what constitutes valid resources, and how these various forms of resources should be distributed. Power struggles over resources are likely to be realized in policy texts (vision statements, guidelines for practice, regulatory frameworks), as well as the internal restructuring and renaming of sections of the education department, and reallocation of resources. Thus, whole sections of the bureaucracy may be reconstructed through these power struggles, and the roles and responsibilities of key policy actors redefined in the process. The stakes are high in these struggles. For the groups that gain power and control over valued resources manage to project their visions of education as the dominant or legitimate vision (Bernstein, 2000). This is not to suggest that the struggles and conflicts between policy actors are necessarily rational, tactical and calculated. Rather, the actions of policy actors maybe governed by the practical logic of specific arenas, as well as socialization into distinctive habits/dispositions through education, training and previous work experiences (see Taylor \& Singh, 1995).

Educational policies are re-contextualized discourses, that is, they are constituted through the selective appropriation of texts from outside the arena of education to form a specialized discourse about education. Moreover, policy texts are subject to multiple recontextualizations not only at the point of production, but also during carriage and implementation. Re-contextualization implies a shift in power and control relations and thus meanings as texts are selectively prised from one context and placed within another. From this perspective, concepts such as inclusion are 'sliding signifiers', that is, concepts 
with no fixed meaning which can be mobilized by various social groups to project their vision of schooling (see Apple, 2002, p.2). Moreover, various groups of policy actors will have access to unequal resources in the social field of power to influence the meanings associated with key concepts, as well as the ways in which these key concepts are articulated or come together to cohere within a dominant discourse about schooling.

In the next section of the paper, we turn our attention to describing our empirical study.

\section{Empirical study of QSE 2010}

\section{Data collection}

We interviewed fourteen 'key players', in eleven separate interviews, about issues of equity and difference in the development and early stages of the implementation of QSE 2010 in late 2002. The policy actors interviewed for the study included relevant senior bureaucrats in Education Queensland and one influential academic/researcher who had been involved in the reforms. Three areas of the bureaucracy (as it was then structured) were represented in the interviews: Strategic Directions, Performance and Measurement; Curriculum and Assessment; and Workforce and Professional Development. In this paper, however, we draw on interviews conducted with the nine policy actors in the two areas most involved with the implementation of QSE 2010: (1) Strategic Directions, Performance and Measurement (SDP\&M) (Policy Actors A, B, C, D); (2) Curriculum and Assessment (C\&A) (Policy Actors E, F, G, H, I).

The interviews pursued the research questions in a dialectical way as part of a 'conversation with a purpose' (Burgess 1984). This approach has been used in other major research studies conducted with key policy actors (eg. Henry et al., 2001). Interview questions explored how equity issues were being framed, what language was used, what specific groups were being targeted, what programs were being funded, and how outcomes were being monitored. Interviews were approximately an hour in length and were audio taped and later transcribed.

\section{Data Analysis}

The interviews provided by the nine key policy actors, as well as the documents collected for the study (research and position papers informing QSE 2010, implementation papers/statements relating to QSE 2010, and internal memos on issues of inclusion and students at educational risk) were analysed in a number of phases. Firstly, the data were coded to quantify how often the terms 'inclusion/inclusive', 'equity', 'difference', 'diversity', and 'risk' were used in the various texts - documents and interview data. In the second phase, individual extracts of data identified in the various policy and discussion documents were analysed to determine the preferred meaning given to the terms: 'inclusion/inclusive' and 'at-risk'. Oppositional meanings were also identified. Many of the documents referred explicitly to the notion of an inclusive public education system. Here the term 'inclusive' public education was contrasted with the exclusive notion of private schooling (Education Queensland, 1999, p.9). Public education was constructed as providing equality of 'access' and 'opportunity to all' (Education Queensland, 1999; 2001b). However, in other documents the term inclusive education signified catering for: 'individual needs and learning styles' (Schofield, 1999a, p.8), 'gifted kids', as well as 'remedial students' (Schofield, 1999b, pp.20-21). These notions of inclusion could only be achieved via 'greater diversity between institutions' (Schofield, 1999b, p.24). At the same time, concerns were expressed that the term inclusion had a discursive legacy and attachment to only one category of students, namely, 'students with disabilities' (Education Queensland, n.d.). Yet again, other documents used the word 'inclusion' to refer to building an 'inclusive society' through notions of 'inclusive citizenship' 'that maintains the well-being of our own diverse communities, and develops respectful relations with others' (Martinez, 1999, p.8, p.9, p.13; see also Edgar, 1999; Education Queensland, 2000). In 
these documents, reference was made to the changing composition of the Australian population, as well as changes to employment patterns, family life, local communities and participation in civil society.

Similarly, the term 'students at educational risk' was used in a number of the documents, including the key paper, 'SM-17: Students at Educational Risk' (Education Queensland, 2000). The term was defined as follows:

'Students at educational risk' are those students whose experience of schooling, together with other factors in their lives, makes them vulnerable to not completing twelve years of schooling or equivalent qualification, or not achieving to their potential, the essential knowledge and skills for effective participation in work, relationships and families, and as active citizens in the community. (Education Queensland, 2000, p.3)

Other documents talked explicitly about curriculum and pedagogy reform to improve educational outcomes for the 'most at risk students' (see Education Queensland, 2001a; Luke, 1999). This was also the main concern of the document titled: 'SM-17: Students at Educational Risk':

Recognising that there is a recurring cohort of students in state schools who are at educational risk, the policy sets out accountabilities at all levels of Education Queensland to support teachers in improving:

(a) the attainments and school completion of students at educational risk;

(b) the quality of engagement in learning and school life at all levels of schooling for students at educational risk; and

(c) the average and distribution of results of students at educational risk to reflect those of the total student population. (Education Queensland, 2000, p.3).

Similarly, the document QSE 2010 (Education Queensland, 2001, p.17) referred to 'a new deal on equity' which entailed, in part, the 'development of a systematic approach to improving outcomes for at-risk groups'. At the same time, however, there was some concern that the terms 'educational risk' and 'at-risk groups' may have negative connotations, and it may be more appropriate to use the word 'educational inclusion' in reference to social justice issues (Education Queensland, n.d.).

In the third phase of analysis, the individual interviews with the key policy actors were divided into episodes relating specifically to: (1) the goals of 'inclusion' for a publicly funded education system; (2) the system and/or student problem of 'educational risk', and (3) the procedures for addressing 'educational risk' and thereby achieving 'inclusion'. In addition, the links between the above three topics, namely, inclusive 'learning' goals of a publicly funded education system, the students excluded or 'at risk' from achieving these goals; and the initiatives, strategies or innovations designed to steer the system towards its utopian ideal were fleshed out. The analysis of the interview data is documented in the following section.

\section{The Mantra of Inclusion}

... certain words and phrases hatched like moths from invisible cocoons: 'closing gaps', 'building partnerships', 'overcoming distances', finding 'common goals'... It was 'binding' rhetoric. The not very attractive word 'inclusive' crept in, and became a mantra of sorts (Watson, 2002: 107-108).

All of the policy actors talked of the importance of developing and implementing a 'new deal on equity' (Education Queensland, 2001, p.17), in the context of the profound social, 
economic and cultural changes often referred to as the global information revolution, as discussed earlier in the paper. However, the positions taken by the policy actors differed markedly. Differences were clearly evident between policy actors who worked in different sections of the bureaucracy, as well as between newer recruits to the Department ('schoolies') and long-term policy actors ('policy people'), and between policy actors with education experience (educationalists), and those recruited from other departments such as health, transport and family services (outsiders). In the following three sections we examine three points of contention between the various policy actors, namely: (1) framing policy with the language of 'inclusion' and 'educational risk'; (2) policy carriage - the global-local equity network; and (3) policy traction - monitoring equity outcomes.

\section{Framing a New Equity Agenda: 'Inclusion' and 'At-Risk'}

Policy Actor (A), from Strategic Directions, Performance and Measurement, reported that he had been involved 'right from the beginning' with the formulation of QSE 2010. He was responsible for 'target setting', 'benchmarking' and ' $a$ lot of the research that underpinned' the document. In the following data extract, he talked about the new approach to equity issues in Education Queensland ${ }^{1}$.

\section{Extract One:}

Researcher (1): ... how do you see that individual focus ... going alongside any kind of target group approach?

Policy Actor (A): Can I answer in a somewhat diverse way? Two of the key research drivers ... for me were two major reports, one was put out by the OECD - entitled 'School Failure'. School failure they defined as any school losing one child without them transferring to another post-secondary education or comparable level. ...The other report came from the European Commission, and it had the same title: 'School Failure.' They defined school failure as any student who fails first year university or first year TAFE postyear 12 without the pre-requisite skills from the school. It's the link between an individualbased approach to explanatory variables to a system-based approach, to what is it we have to do as a system to become inclusive in terms of the diversity and responsiveness to our needs. ... But until you have a real hard edge on some of these issues you don't force the debate. When you are looking at this, you put values under the table - full stop - and increasingly you have an inclusive approach to education.

\section{A number of lines deleted}

Policy Actor (A): And, obviously, what I've articulated here is an inclusive model, that is, diametrically opposed to a model where you have a traditional 1970s, 1980s equity approach. It doesn't mean that we're not interested [in equity issues]. It's a systems approach for how you do it

\section{A number of lines deleted.}

Policy Actor (A): It's not that we're [against the strategies used by people in the former equity branch of the department]... it's just the battle of the debate about what's more effective in terms of intervention strategies.

Researcher (1): I can see there have been problems with, in the past, with the target group approach for all sorts of reasons.

Policy Actor (A): So we have one target group now and that's every kid - full stop.

(Interview with Policy Actor A, SDP\&M)

We want to highlight two main points in the above extract of data. The first point relates to the recontextualization of reports produced by the OECD and European Commission in order to inform the policy agenda of Education Queensland. A number of researchers have suggested that a neo-liberal global policy orthodoxy has been produced by a transnational elite of policy actors and constitutes part of an alignment with supranational organizations such as the Organization for Economic Cooperation and Development (OECD), the World Trade Organization (WTO), the World Bank, the International Monetary Fund (IMF), and 
the European Union (Ball, 2003; Henry et al, 2001; Stromquist, 2002). This alignment deal opens up the economies of these countries, 'in all sectors, to global capitalist institutions' (Ball, 2003, p.31). According to Stephen Ball, this neo-liberal orthodoxy typically combines the following elements: 'competition, choice, devolution, managerialism and performativity' (Ball, 2003, p.30). While there may be an emerging global consensus about educational policy and reform, local contexts and actors are likely to shape the specific form of local educational discourses and practices (see Appadurai, 2000). On this point, Lingard (2000, p.80) suggests that 'the apparent educational policy convergence across nations' is 'mediated, translated and recontextualized within national and local structures'. This is the tension between "“context-productive" (top-down and policy driven) and "context-generative" (localized) practices', which are produced by the multidirectional flows of cultural globalization (Appadurai, cited in Lingard, 2000, p.80). In terms of the new deal on equity for Education Queensland, there was no evidence that neo-liberal global orthodoxy on education was simply appropriated in a top-down, one-way flow of educational discourses. Rather, Policy Actor (A) had apparently been actively involved in formulating policies in these supranational organizations. At the same time, however, he was engaged in selectively recontextualizing elements of these supranational discourses to inform local practices.

The second point is the concerted attempt to challenge existing equity discourses and replace these with a new policy orthodoxy geared to individual tracking and monitoring of students. In general terms, this approach was consistent with the global discourse of neoliberalism which simultaneously calls for less government intervention through devolution of governance and financial responsibility to local levels, and greater state centralized control through accountability or performativity measures (see Stromquist, 2002, p.6; Lyotard, 1985). The objective of this data-driven regime was to capture patterns of success and failure in order to devise system-based strategies or interventions for addressing the problem of 'school failure'. Policy Actor (A) suggested that this approach was designed to be 'pro-active' and interventionist - capturing data, working out explanatory variables, finding out what works, and extending success stories through networks. According to Policy Actor (A) centrally defined performance targets should be viewed as mechanisms for generating localized innovative practices designed specifically to improve the educational outcomes of all students.

The position taken by Policy Actor (F), a new recruit to the education bureaucracy, as well as to the area of Curriculum and Assessment, was very similar to that adopted by policy officers working in the area of Strategic Directions, Performance and Measurement. Policy Actor (F) argued that the shift to 'at-risk' language, and away from the term 'disadvantaged students' represented a move away from 'blaming the individual' to focussing on organizational failures. However, as Stephen Ball (2003) has noted, organizations and individuals have different capabilities and resources for managing risk. And schools and school districts in impoverished socio-economic areas are likely to be further disadvantaged by this individualized, market-choice discourse of risk management.

\section{Extract Two:}

Researcher (2): So can we just pick up on that point? It's a notion of shifting the language in a sense - and then, I assume, shifting the way that that language represents a group of people.

But also doing something at an organisational level?

Policy Actor (F): I suppose, the shift in the language is that I wouldn't use the term 'disadvantaged' students. I would use the term 'students at educational risk'.

Researcher (2): Right. Why?

Policy Actor (F): And the reason why I wouldn't use 'disadvantaged' students is that ... it puts the characteristic on the student. Whereas, in actual fact, it's an interaction. That - we all come to the system with our own backgrounds. And the requirement is that the system 
responds to us in a way that doesn't disadvantage us. Not necessarily because I'm disadvantaged. But the system doesn't disadvantage us. So we would use a term 'at educational risk' because that puts the onus or the focus on the system, rather than on the individual.

A number of lines deleted.

Policy Actor (F): So, for instance, we would still provide funding or differential funding to schools where there is lower socio-economic status. Or where there is lower performance on standardised tests. Or where there are more indigenous students. So we are still providing resources - differentially - but we are trying to build the ownership of the school in terms of the issues for their population.

(Interview with Policy Actor F, C\&A)

By contrast, Policy Actor (G), also employed in the Curriculum and Assessment area, was very critical of the terms 'inclusion' and 'at-risk' in relation to an equity agenda for the department. Policy Actor $(\mathrm{G})$ had worked in the equity area for a long time, and claimed to have witnessed the dismantling and/or whittling down of equity initiatives since the mid 1990s. At the same time, however, she was adamant of the need to change the way educational equity was conceptualized and implemented. Specifically, Policy Actor (G) argued that the social justice target group agenda of the 1990s no longer worked in the new millennium ${ }^{2}$. Policy Actor $(G)$ nominated five reasons for the need to re-conceptualize educational equity. In her view, the target group social justice strategy did not:

(1) effectively 'address issues of poverty' [because] there was 'no voice for it';

(2) promote effective communication between policy officers working on different equity initiatives for specific target groups,

(3) focus on 'kids as complex human beings', and therefore produce professional development workshops that captured the whole rather than 'slices' of students' 'humanity',

(4) research the new equity priorities created by the massive social, cultural and economic changes associated with globalization and the new technologies; and

(5) deal with the 'huge backlash against feminist educators', and the rearticulation of gender to signal 'boys' education'.

However, Policy Actor (G) did not agree with the new directions proposed for equity initiatives in the department. In particular, she was highly critical of the framework for 'Students at Educational Risk', arguing that it placed the responsibility for identification of equity needs onto principals and local schools, and thereby emphasised a 'deficit' thinking approach. At the same time, she argued that the language of 'inclusion' was still underpinned by a discourse of disability, because it was originally used to refer to the inclusion or mainstreaming of students with disabilities in the Queensland context (a point also made by Policy Actors E and F).

\section{Extract Three:}

Policy Actor (G): We're now in a situation where our key policy document is the framework for 'Students at Educational Risk' and I see it, no matter how we try to structure it to not be about deficit, it is read like that in schools and one of the key reasons for that is that in the principal's accountability - as the first one - is to identify students at educational risk.

Reseacher (2): ... I thought the shift in the language - 'students at educational risk' was an attempt to get away from the target group deficit outlook but you're saying it's, in fact, reinforcing it.

Policy Actor (G): It's moving away from target groups, and it's emphasised deficit.

Researcher (2): And the deficit lies with the individual?

Policy Actor (G): The deficit lies with identification, I suppose you would say. They might identify a whole group, or an individual student in the process of identification, and then 
they've got to have specific strategies, specific to the needs of that student/or group. Now we did try to get around that by talking about - you know - the focus of this is, really, engagement - it's on the resources that do exist in communities, not those that are absent. It's on every kid's life experience as a resource for learning. ... And we've got the framework of 'Students at Educational Risk' which is widely interpreted as deficit even though we tried to rescue it from that. And we've got a new language that is mainly about disability. The language about inclusive education - is about inclusion but it's got a heavy kind of underlay of disability to it.

(Interview with Policy Actor G, C\&A)

In the preceding section, we examined the discursive shift in the education equity agenda from a language of 'social justice target groups' to 'inclusion' and 'students at educational risk'. We suggest that the language of 'inclusion' became the new mantra for talking about an equitable schooling system in Queensland. Although the language of inclusion aimed to bind together warring parties and multiple interest groups/stakeholders, there appeared to be no consensus on what the term meant, nor any policy strategy or framework specifically about 'inclusion'. At the same time, while the department did have a framework for 'Students at Educational Risk', many of the policy actors were uncomfortable with the language of 'at-risk' and 'educational risk' suggesting that it had individualistic deficit connotations. Other policy actors working in the area of Strategic Directions, Performance and Measurement suggested that the 'at-risk' language was designed to focus attention on the deficiencies within the system, that is, school failure.

The reformulation of equity issues in individualistic terms was clearly a 'marketindividualistic' approach (Henry, 2001) - a shift from 'social distribution' to managing 'individual at-riskness'. The conflict within the department raged not only over 'issues of identification' - who is 'at-risk' and how do we know; but also over 'intervention' strategies - what should be done to address equity issues. The focus on 'school failure' increasingly devolved responsibility for both 'identification' and 'intervention' to the level of the school. But as Stromquist (2002, p.28) has argued these 'principles of equity now operate in parallel with reductions in government support for public education'. Consequently, the 'drive for student success ends up placing responsibility (and thus blame) on parents, students, schools, and teachers' (Stromquist, 2002, p.28).

\section{Policy Carriage for the New Equity Framework}

Between the political impulse and the political consequence lies a hall of mirrors. You throw an idea in - you may throw it in several times - but how it is seen and what reaction it provokes depends on forces largely beyond your control. It is a random business ... (Watson, 2002, p. 562).

All of the policy actors talked about a departmental move away from centralised policy making, dissemination and implementation. Devolution of decision-making is a key element of the new global education policy orthodoxy. The old 'policy roll out' approach was considered to be ineffective for a number of reasons, including: the pace of change, and the increasingly global-local networks of schools. For example, Policy Actor (E), from Curriculum and Assessment, argued that some of the policy officers within the bureaucracy were 'behind ... some schools' in terms of 'their grasp of practice and policy development and theory', because these schools had been 'networking with schools and authorities in America or England or wherever'. In addition, some of the policy actors were 'no longer at the front' in terms of their 'areas of expertise'. Thus, the work of the policy actors had to change to a much more 'networked and connected' approach, that was 'far more connected to what's going on nationally and internationally, and connected with what's happening out in schools and districts’. (Interview with Policy Actor E, C\&A). 
By contrast, Policy Actor (G) talked about an 'anti-policy environment' within the bureaucracy, and the move from a 'rowing' to a 'steering' approach to educational change and governance.

\section{Extract Four:}

Policy Actor (G): ... there is not a great deal of new policy coming out of Education Queensland. There's an anti-policy environment. And I can understand that. I think the old idea that you change a system with policy is not one that you can really believe in. The framework for 'Students at Educational Risk' - is that it was constructed as a steering, not rowing policy. The Senior Policy Actor responsible for driving that policy, saw it as something where the accountabilities were clearly allocated, expressed specifically, and those people had to do that, and we got out of the way.

(Interview with Policy Actor G, C\&A)

Such an approach to policy, however, assumes that various people allocated with accountabilities and responsibilities, have the necessary resources, skills and time to carry out this work. It also assumes that people in schools, and at the district education level, are willing to make 'counter-cultural' or innovative changes because 'good teaching ... in disadvantaged schools ... requires maximum flexibility and imagination (Connell cited in Symth, 2004: 23). Often teachers ways of thinking about issues of equity and schooling are framed around 'local and vernacular theories and practices of having to deal with the diverse, often fractured, and fragmented lives of children' rather than in terms of the discourse of contemporary policy, that is, the language of 'rating, ranking and "education by numbers” (league ladders and cross-school comparisons)' (Symth, 2004, p.23). Finally, there is an assumption of similar understandings of terms such as 'inclusion' and 'at-risk' even though these terms had not been clearly defined, and a consensus had not been achieved about the meaning of these terms within the various areas of the central bureaucracy. As Symth (2004: 23) argues the discourses of contemporary policy and the lifeworlds of teachers in disadvantaged schools are often 'incommensurate'.

\section{Extract Five:}

Policy Actor (G): ... there's not a great deal of new policy. The inclusive education direction is just that ... There's a working definition that came from the summit but that only applies to the summit. That's something that belongs to the people who were at that summit.... There is a commitment to meetings being made through collaborative networks like list servers and things like that. To opening it up and making it - you know - so I suppose democratising it - that's what gives validity to a meaning. That those people are involved in it, you know, own it, et cetera. So we don't have a definition of inclusive education. It's an idea. And in terms of other policy, well, I think there is a very, very narrow group of people in here who recognise that we've got a big hole in terms of social justice policy.

\section{(Interview with Policy Actor G, C\&A)}

The weakest aspect of QSE 2010, according to Policy Actor (G), was in the area of policy carriage. It was a 'landmark' strategy, and a completely new way of 'doing policy work'. But its greatest weakness was in the translation from general philosophical statement, vision or 'strategy' to action plans for practice. Consequently, another document, Destination 2010 (Dept. of Premier and Cabinet, 2002), was designed to assist with policy carriage. Specifically, Destination 2010 nominated the areas of responsibility and accountability in terms of monitoring and measuring educational outcomes - 'proving' rather than 'improving' as Policy Actor (G) put it. In other words, Destination 2010 became a checklist technical document used by school principals to show that respective schools were meeting the performance targets set by central office. The document thus worked to constitute a managerial and/or business culture within schools. In general terms, managerialism embraces 'restructuring, accountability, performance or 'performativity', 
and measurement of educational activities as solutions to both social and educational problems' (Boshier, 2000 cited in Levin, 2001, p.64). According to Policy Actor (G), the technical outcomes or performativity language of Destination 2010 silenced 'issues like the new concentrations of poverty or mobility of different types of families'.

Policy Actor (G) also expressed concern with which sector of the bureaucracy was given responsibility for policy carriage. If accountability was to be devolved to the school and district level, and measured by performative outcome criteria, then what role would people in 'professional development' and qualitative data analysis play in the policy process? And how would 'improvement' in learning outcomes be measured within and between schools?

In the preceding section, we examined struggles over policy carriage or recontextualization. Specifically, we argued that the place or role of policy in departmental governance changed substantially from a 'rowing' to 'steering' approach. Thus, QSE 2010 was not written as a traditional policy paper, but rather as a vision statement or strategy. As such, the document attempted to somewhat subvert the neo-liberal global policy orthodoxy by building a vision of education that addressed issues of poverty, active citizenship, social exclusion and social cohesion. However, the responsibility for enacting this vision was placed in the hands of schools and teachers. These were the reflexive agencies and agents of late modernity that would be able to monitor and manage risks in order to produce innovative educational practices. And yet this is where the strategy or vision was weakest because it did not articulate clear plans for 'policy roll out'. Thus, it left a vacuum in terms of professional development and accountability measures - two instruments or technologies of policy carriage. This vacuum was filled by the document Destination 2010 (Dept. of Premier and Cabinet, 2002) - a managerialist discourse of accountability and performativity.

\section{Policy Traction for the New Equity Agenda}

The unceasing conflict at the centre of politics is essentially epistemological ... Politics is the art of the knowable. The protagonists usually divide between the empirical and statistical and the psychological and anthropological. There is the science of polling, the wisdom of experience and the hunch or instinct. There is the ideological and the imagined, the empathetic (Watson, 2002, p.84).

Clearly the central point of contention between the various policy actors, and particularly between those who worked in the area of Curriculum and Assessment, and those who worked in Strategic Directions, Performance and Measurement, was about epistemology Who is at educational risk? How do we know? And what strategies might make an educational improvement? The protagonists were divided along the lines of 'the empirical and statistical' and 'the wisdom of experience', as Watson (2002, p.84) has described.

Thus, Policy Actor (G) talked about the process by which 'the data people' who 'put together all these graphs and pie charts and whatever' came to 'own' the equity issue. This was clearly a strategy to divorce specialist knowledge from equity policy actors and place it in the hands of measurement people - quantitative data analysts (see Bernstein, 2000).

\section{Extract Seven:}

Policy Actor (G): ... The data people weren't telling us anything new. But left most of us not able to participate in a conversation where it ...came to be about data. About data, really. So it became a data issue rather than a 'Let's create a more accessible way of talking about kids and their lives and their families' - that draws attention ...to the complexity of their lives. 
Moreover, both Policy Actor (G) and Policy Actor (F) talked about the limitations of the data actually produced by the department to monitor learning outcomes, and equity strategies. It will be recalled that Policy Actor $(G)$ also took issue with the new strategies for identifying 'at-risk' students - responsibility for data production rested with individual principals and schools. This was essentially a concern about the knowledge and resources available to principals to make informed decisions in relation to risk management. In addition, Policy Actor $(G)$ was concerned about the so-called feedback loop between localised data production and 'whole-of-system' strategies. Specifically, Policy Actor (G) argued that 'there's almost nothing you can pick up by way of information that can tell you how well a policy is going. There's no aggregation of that information in a storied sort of way'. Similarly, Policy Actor (F) commented on the limitations of the available data.

\section{Extract Eight:}

Researcher (2): Right. So what kind of data would you collect from these schools or regions or how does that actual system work? Because that seems very intriguing for me and then what do you do with that knowledge?

Policy Actor (F): Yes. I think that the perception is probably more advanced than reality. In that there's not a lot of data collected at schools and reported back on - or - that is high level data. There are all the standardised assessments, but then the problem with those assessments is that a lot of students who have English as a Second Language, or who are Aboriginal or Torres Strait Islander, or who have a disability, are exempted from all those standardised assessments. So all that data doesn't really help us with knowing how we're doing in schools. The qualitative data is collected in an ad hoc way so that there's no - we currently don't have a real mechanism to actually look at how that's looking across the board. What we do do, is every year, is try and undertake a qualitative analysis of the implementation of the 'students at educational risk policy' so we try and collect information from schools and it's mostly like dialogue about how they've gone about attempting to improve things and then how they have seen that being achieved and so that we can document - you know - the stories of success within schools.

Researcher (2): So when you dialogue - what - your team goes out?

Policy Actor (F): Yes, people go out and actually talk with schools. But it is not - there's not a lot of actual hard data and so there's nothing that comes in here that we use as a branch to really identify - like, how we're doing.

A number of lines deleted.

So in some areas there is some data, but generally speaking we are very data poor.

(Interview with Policy Actor F, C\&A)

The positions taken up by Policy Actors G and F, however, stood in stark contrast to those adopted by policy actors working within the Strategic Directions, Performance and Measurement area.

\section{Extract Nine:}

Policy Actor (A): Once you start tracking every single kid in the State you start seeing some obvious patterns. You start seeing some obvious success stories and you start seeing ways to build bridges between schools that are significantly delivering and those that are not. You then put in place the analytical framework to allow those sorts of research areas to go ahead. We need to have initial research to actually find out what's happening.

(Interview with Policy Actor A, SDP\&M)

Similarly, Policy Actor (B) who worked in the area of Strategic Directions, Performance and Measurement suggested that the approach adopted by the department was designed to achieve 'best practice' for all students based on empirical evidence. Moreover, the evidence-based 'feed-back loop' was designed to encourage innovation and unhinge the holds of tradition. This was clearly a reflexive research driven strategy aimed at risk management. Moreover, it was a strategy designed to encourage innovation through 
effective techniques of risk assessment and dealing with uncertainty through data production and analysis.

\section{Extract Ten:}

Policy Actor (B): ... it is really about ...having a performance measurement system that collects, collates, reports and disseminates information back. So it's really a large feedback loop - its really about making the best use of resources and break that nexus of tradition around things being done because they have always been done in a particular way and saying "Well, look what the evidence is there and this works and this doesn't work". So there are some tough questions being asked around divestment. I think it is a much more objective way of creating policy because it is not necessarily driven by political imperative, because at the end of the day we are looking at what works.

(Interview with Policy Actor B, SDP\&M)

However, the data-driven positions taken by Policy Actor (A) and Policy Actor (B) were challenged by Policy Actor $(\mathrm{C})$, a new recruit into the education bureaucracy and the area of Strategic Directions, Performance and Management. Policy Actor (C) described herself as a 'schoolie' rather than a policy person. Her concern was to ensure that the data collected at the school level led to 'professional dialogue' within and between schools. Thus, Policy Actor (C) picked up the incommensurable discourses of contemporary policy and the lifeworld of teachers. Her challenge was to generate a professional teacher discourse about effective educational practices drawing on data generated at the local level. Data generation was to be used to improve rather than just prove school practices as Policy Actor $\mathrm{G}$ had noted above. However, improvement of educational practices was not likely to occur without adequate professional development taking place at the level of the school.

\section{Extract Eleven:}

Researcher (1): Are you going to do anything about monitoring any of the equity groups? Policy Actor (C): ... we were setting up the data so we could see the value-added-ness for a particular school. We didn't want to just compare the State benchmarks or like schools we wanted to see the distance travelled ... What I worry about is - you know - unless you have a really good informed person - they won't know what data to produce or how to make sense of it, and what strategies to put into place to change learning outcomes.

A few lines deleted.

Policy Actor (C): ... I know the Director General [places a lot of importance] on data and targets, and you need that. But I really have an absolutely deep-seated belief that it's the power of the question and the conversation that changes the mindset - you can use data to provoke that, and you never know the impact of the question. [In my experience] teachers can be engaged in professional dialogue about [challenging] questions ... now that is change - ...classroom teachers having a professional dialogue ... and actually seeing that they have made a difference. That's what I think is the most powerful. That's what I like to do and that's what I want executive directors to do and principals to do.

(Interview with Policy Actor C, SDP\&M)

It could be argued that risk management against school failure was placed at the hands of school principals and teachers at the level of the school and school district. However, the policy actors all differed in terms of the type of knowledge needed at the local level to manage risk. The term risk has both negative and positive connotations - simultaneously referring to the avoidance of unwanted outcomes through adherence to regulatory frameworks, as well as the generation of innovative practices as the state delegates responsibility for performance outcomes to institutions (Giddens \& Pierson, 1998). Moreover, some of the policy actors clearly argued that the knowledge needed to do the symbolic work of risk management was differentially distributed - school personnel simply didn't have the time or resources to produce or collate information to engage in effective risk management strategies. Indeed, Stephen Ball (2003, p.150) argues that 'risk constantly 
reinforces responsibility and the values of the developmental self'. This leads to the 'rise of a new form of inequality, that is, "the inequality of dealing with insecurity and reflexivity", (Ulrich Beck cited in Ball, 2003, p.150). Risk and risk management within a 'privatized and more open post-welfare, choice' system is considered to be:

... an inherent characteristic of the market form, an essential part of its dynamic, a quality that is celebrated and set over and against the conservatism of bureaucratic systems. The market form rests on responsibility, skills and resourcefulness and an absence of uncertainty. ... Part of the riskiness of the postwelfare, choice system ... inheres in the importance and elusiveness of useful and accurate information. (Ball, 2003, p.151)

\section{Discussion}

The case study of QSE 2010 illustrates the impact of global trends on educational policymaking, and in particular on the ways in which equity issues were being framed and addressed. Although equity issues were still on the reform agenda, the approach taken to address educational disadvantage could be said to be a market-individualistic approach (Henry, 2001). There was a discursive shift away from the language of 'social justice' and 'target groups', towards 'inclusion' and 'students at educational risk'. However, there were differing views among the bureaucrats who were interviewed about the meaning of the terms. In addition, while some were concerned that the focus on 'students at educational risk' suggested individual deficit notions, others suggested that the term was intended to focus attention on system and school failure. We argued that while a 'target group' approach to equity was a limited means of addressing social disadvantage in the new millennium, a market-individualistic approach was an inadequate alternative.

The research highlighted the move away from centralised policy making towards school based management which is consistent with a neo-liberal global policy agenda. With policy adopting a 'steering' rather than a 'rowing' approach, the responsibility for enacting the QSE 2010 vision was placed in the hands of schools and teachers. In the absence of professional development, concerns were expressed about how well principals were able to make informed decisions about students 'at risk'. There were clear divisions within the bureaucracy about the role of data in identifying students who were 'at risk', and what kind of data were needed, with some committed to 'evidence based management' and the use of quantitative measures, and others who felt that more nuanced qualitative school based data were needed.

In the original QSE 2010 document the tensions between the local and the global were clearly evident (Taylor and Henry, 2003). In the response to rapid global pressures for change, economic priorities could be seen to be interwoven with social goals throughout the document. There was a strong emphasis on social capital as well as human capital, and on public schooling in the document. In many ways, QSE 2010 was a far reaching strategy for educational reform, where local imperatives for social justice were combined with global imperatives. However, as the agenda has played out, and has been implemented within the bureaucracy, the pressures of the global agenda have become dominant, with the individualised 'risk' focus, devolved management and the influence of performativity weakening the social agenda.

A further feature of the policy processes highlighted in the research, was that the debates over the framing and managing of equity issues within the bureaucracy tended to reflect the differing locations and competing interests of the policy actors we interviewed. There were differences between those who were more concerned with system issues in the Strategic Directions, Performance and Measurement section, and those who tended to be more school focused in the Curriculum and Assessment section (see Taylor and Singh, 2005). 
At the heart of these differences and debates in the policymaking processes within the bureaucracy were struggles over language. Of course there are no absolute meanings for the terms which are used in relation to equity and social justice: differences in terminology reflect the historical, cultural and political contexts in which they are constructed and used. The terms associated with equity issues are particularly malleable, and as Apple (1993, p.49) has observed, 'Concepts do not remain still for very long. They have wings, so to speak, and can be induced to fly from place to place. It is this context which defines their meaning'. However, language has effects in real terms. In the absence of any clear policy directives, the general lack of consensus about the meaning of the new terminology, and the disagreements about what needed to be done, there were significant obstacles to the implementation of the 'new deal on equity'.

\footnotetext{
${ }^{1}$ All names have been replaced by letters of the alphabet to ensure confidentiality. Researcher $(1)=$ Sandra Taylor, Researcher (2) = Parlo Singh. For the sake of clarity, data extracts have been edited. 2 The student groups and characteristics targeted in the Social Justice Strategy were: Aboriginal and Torres Strait Islander students, Cultural and language diversity, Disability, Educational Risk, Geographical Isolation, Gifts and Talents, Learning Impairment and Learning Difficulty, and Low Socioeconomic Background (Department of Education, 1994)
} 


\section{References}

Appadurai, A. (2000). Grassroots Globalization and the Research Imagination. Public Culture; Society for Transnational Cultural Studies, 12(1), 1-19.

Apple, M. (1993) Thinking right in the USA: ideological transformations in an age of conservatism, in: R.Lingard, J. Knight, and P. Porter (Eds) Schooling Reform in Hard Times (London: Falmer Press).

Apple, M. W. (2002). Patriotism, Pedagogy, and Freedom: On the Educational Meanings of September 11. Retrieved March 24, 2004, from http://www.tcrecord.org/Content.asp?ContentID=10939

Ball, S. J. (2003). Class Strategies and the Education Market. The Middle Classes and Social Advantage (London, New York: Routledge Falmer).

Ball, S. J (1990) Politics and Policy Making in Education. Explorations in Policy Sociology (London: Routledge).

Bernstein, B. (2000). Pedagogy, Symbolic Control and Identity (Revised Edition) (New York and Oxford: Rowman \& Littlefield Publishers, Inc.).

Bowe, R., Ball, S.J. \& Gold, A. (1992) Reforming Education and Changing Schools. Case Studies in Policy Sociology (London: Routledge).

Burgess, R. (1984) In the Field: an introduction to field research (London: Allen and Unwin)

Castells, M. (2000) End of Millennium. The Information Age: Economy, Society and Culture (Second ed. Vol. 111) (Oxford: Blackwell Publishers).

Cole, M. (2003). Might It Be in the Practice that It Fails to Succeed? A Marxist Critique of Claims for Postmodernism and Poststructuralism as Forces for Social Change and Social Justice. British Journal of Sociology of Education, 24(4), 487-500.

Cullen, R., Cosier, I., Greco, F., \& Payne, J. (1999) Participation and Attainment Targets for Queensland Schools (Brisbane: Education Queensland).

Department of Education, Queensland (1994) Social Justice Strategy: Issues and strategies (Brisbane: Government Printer).

Department of Premier and Cabinet (2002) Queensland the Smart State. Education and Training Reforms for the Future (Brisbane: Queensland Government).

Dwyer, P., \& Wyn, J. (2001). Youth, Education and Risk. Facing the Future. London: RoutledgeFalmer.

Edgar, D. (1999) Learning to live with complexity (Brisbane: Education Queensland).

Education Queensland (1999) Queensland State Education 2010: Government's Role in Education (Brisbane: Education Queensland).

Education Queensland (2000) SM-17: Students at Educational Risk (Brisbane: Education Queensland).

Education Queensland (2001a) Queensland School Reform Longitudinal Study: A strategy for shared curriculum leadership. Teacher's summary 2001 (Brisbane: Education Queensland).

Education Queensland (2001b) Queensland State Education 2010 (Brisbane: Education Queensland).

Education Queensland (2002) schools + parents (EdQld magazine for parents) (Brisbane: Education Queensland).

Education Queensland (n.d.) Rationale for a Review of the Framework for Students at Educational Risk (Brisbane: Education Queensland).

Foucault, M. (1979). Governmentality. Ideology and Consciousness, 6(Autumn), 5-46.

Foucault, M. (1990). The History of Sexuality. An Introduction: Volume 1. New York: Vintage Books.

Gale, T. \& Densmore, K. (2003) Engaging Teachers. Towards a radical democratic agenda for schooling (Maidenhead/Philadephia: Open University Press).

Giddens, A., \& Pierson, C. (1998) Conversations with Anthony Giddens. Making Sense of Modernity (Stanford, California: Stanford University Press). 
Henry, M. (2001) Policy approaches to educational disadvantage and equity in Australian schooling (Paris: International Institute for Educational Planning).

Henry, M., Lingard, B., Rizvi \& Taylor, S. (2001) The OECD, Globalisation and Policy Making in Education (Oxford: Pergamon Press).

Levin, J. S. (2001) Globalizing the Community College. Strategies for Change in the Twenty-First Century (New York: Palgrave).

Lingard, B. (2000) It Is and It Isn't: Vernacular Globalization, Educational Policy, and Restructuring, in: N. Burbules \& C. Torres (Eds) Globalization and Education. Critical Perspectives (pp. 79-108) (London, New York: Routledge).

Luke, A. (1999) Education 2010 and new times: Why equity and social justice still matter, but differently, http://education.qld.gov.au/corporate/newbasics/docs/onlineal.doc

Lyotard, J.-F. (1985). The Postmodern Condition: A Report on Knowledge. Minneapolis: University of Minnesota Press.

Martinez, L. (1999) Equity paper (Brisbane: Education Queensland).

Schofield, K. (1999a) The Purposes of Education 2 (Brisbane: Education Queensland).

Schofield, K. (1999b) The Purposes of Education 3 (Brisbane: Education Queensland).

Stromquist, N. P. (2002) Education in a Globalized World. The Connectivity of Economic Power, Technology, and Knowledge (New York, Oxford: Rowman \& Littlefield Publishers Inc.).

Smyth, J. (2004). Social capital and the 'socially just school'. British Journal of Sociology of Education, 25(1), 19-33.

Taylor, S. (1997) Critical policy analysis: exploring contexts, texts and consequences, Discourse: Studies in the Cultural Politics of Education, 18(1), 23-35.

Taylor, S. \& Henry, M. (2003) Social justice in a global context: Education Queensland's 2010 Strategy, International Journal of Inclusive Education, 7(4), 337-355.

Taylor, S. \& Singh, P. (2005, in press) The Logic of Equity Practice in Education Queensland 2010, Special Edition of Journal of Educational Policy, 20(6).

Watson, D. (2002) Recollections of a Bleeding Heart. A Portrait of Paul Keating PM (Sydney: Random House). 